\title{
MATEMATICATIVA: AÇÕES EXTENSIONISTAS PARA POPULARIZAR A MATEMÁTICA
}

\author{
MATEMATICATIVA: EXTENSIONIST ACTIONS TO POPULARIZE
}

MATHEMATICS

\section{PAULA ROGERIA LIMA COUTO ${ }^{\mathrm{a}}$ XIMENA MUJICA ${ }^{\mathrm{b}}$ FERNANDA BUHRER RIZZATO ${ }^{c}$ NATHALIE APARECIDA FELICETTI LUVISON ${ }^{\mathrm{d}}$}

\begin{abstract}
Neste artigo, abordamos de forma descritiva as ações e métodos do projeto de extensão intitulado MatematicATIVA, da Universidade Federal do Paraná (UFPR). Além disso, apresentamos duas pesquisas realizadas para avaliar o projeto, a saber, uma com os estudantes de graduação em Matemática e outra com os estudantes do Ensino Básico (EB), público-alvo principal. Concluímos que o projeto teve um grande impacto na formação dos alunos da UFPR, teve boa aceitação pelos alunos do Ensino Básico e que cumpriu seu objetivo de estimular o interesse pela Matemática.
\end{abstract}

Palavras-chave: Extensão, Matemática, Exposição, Lúdico.

\section{Abstract}

In this article, we approach in a descriptive manner, the actions and methods of an extension project entitled MatematicATIVA, developed at the Federal University of Paraná (UFPR). In addition, we present two surveys carried out to evaluate the project's actions, namely, one with undergraduate students in Mathematics and another with Basic Education (EB) students, the latter being our main target audience. We came to the conclusion that the project had positive impact on training the students at UFPR, there was good acceptance by students in Basic Education and it fulfilled its goal of stimulating interest in Mathematics.

Keywords: Extension, Mathematics, Exhibition, Ludic.

MSC2020: 97

${ }^{a}$ Departamento de Matemática - DMAT, Setor de Ciências Exatas -EXATAS, Universidade Federal do Paraná - UFPR, Curitiba, Paraná, Brasil. E-mail: paulacouto@ufpr.br

${ }^{b}$ DMAT/EXATAS/UFPR, Curitiba, PR, Brasil. E-mail: xmujica@ufpr.br

${ }^{\mathrm{c}}$ Departamento de Estatística - DEST, EXATAS/UFPR, Curitiba, PR, Brasil. E-mail: fernandab@ufpr.br

${ }^{\mathrm{d} U F P R}$, Curitiba, PR, Brasil; E-mail: nathalie.fluvison@gmail.com 


\section{Introdução}

A ideia de popularizar a Matemática pode parecer contraditória uma vez que ela se faz presente em toda a Educação Básica e é reconhecida por ser extremamente necessária para o desenvolvimento científico e tecnológico da humanidade. Entretanto, sabe-se que ela causa aversão a muitos e sua compreensão é tida como algo difícil.

Em 1989, foi afirmado em [4], que havia poucas ciências, se é que existia alguma, que suscitassem reação tão negativa ou mal entendimento, como a Matemática.

Neste sentido, no Brasil, vários recentes movimentos foram desenvolvidos para divulgar e promover a Matemática, não só entre os matemáticos, mas para a população em geral. Por exemplo, 2017-2018 foi decretado o biênio da Matemática no Brasil. Nestes dois anos, ocorreram eventos internacionais importantes para a Matemática mundial na cidade do Rio de Janeiro e outras grandes ações, como o Festival de Matemática 2017, com o intuito de popularizar a Matemática, proporcionando a milhares de pessoas vivenciar e acompanhar atividades na área de Matemática, na esperança de fazer com que crianças, jovens e adultos despertem o gosto pela Matemática e se encantem com seus desafios [2].

No Festival de Matemática 2017, atividades como exposições, oficinas e palestras foram oferecidas em vários locais, como escolas, para a comunidade em geral, com o objetivo de mostrar novas formas de vivenciar e descomplicar a matemática, por meio de aplicações fáceis e criativas, que a matemática apresenta no nosso dia a dia [3].

O projeto de extensão MatematicATIVA da UFPR foi elaborado e proposto em sintonia com o Festival de Matemática 2017, compartilhando do mesmo espírito, de querer mostrar que a Matemática pode ser divertida e de querer desmistificá-la como uma disciplina complicada e para poucos.

O projeto MatematicATIVA começou em maio de 2017, inicialmente com duração de dois anos e atualmente está na sua segunda edição. Ele possui vínculo com o curso de Matemática da Universidade Federal do Paraná (UFPR) - Campus Curitiba. Seu objetivo central é o de proporcionar ao aluno o contato com temas da Matemática que são pouco ou não são explorados nas aulas de Matemática, que possam incentivar o aprofundamento do que é aprendido em sala de aula ou a descoberta de abordagens diferentes da Matemática, seja numa aplicação ou no desenvolvimento da própria Matemática. O público-alvo do projeto é constituído de alunos do Ensino Básico (Ensino Fundamental II e Ensino Médio) e, preferencialmente, alunos de escolas da rede pública de ensino. 
Para tanto, os participantes do projeto (coordenação, orientadoras, palestrantes e alunos dos cursos de graduação, sejam como voluntários, bolsistas ou colaboradores) se prepararam para ir até as escolas de Ensino Básico da região metropolitana de Curitiba, para levar tais temas na forma de palestras e exposições. Nestes eventos, os alunos de graduação e professores do Ensino Superior tiveram a oportunidade de compartilhar com os alunos do Ensino Básico, de forma interativa e divertida, conhecimentos sobre diversos assuntos da Matemática básica e superior, além de compartilhar informações sobre a universidade, principalmente sobre os cursos de Graduação em Matemática que ela oferece.

Desta forma, o presente trabalho tem por objetivo descrever as ações e os métodos do projeto, bem como tecer algumas reflexões acerca do impacto na formação dos estudantes de graduação envolvidos e da recepção do projeto pelos alunos do Ensino Básico.

Este trabalho está organizado da seguinte forma: na Seção 2 será apresentada a metodologia adotada para a execução do projeto e uma descrição das atividades desenvolvidas nas escolas, a saber exposições e palestras. Na Seção 3 será apresentada a metodologia de avaliação do projeto e o resultado da avaliação dos três anos iniciais do projeto. Finalmente, na Seção 4 fazemos a conclusão.

\section{Descrição do Projeto}

O projeto MatematicATIVA foi criado para proporcionar ao aluno do Ensino Básico, preferencialmente de escolas da rede pública de ensino, o contato com temas da Matemática que são pouco ou não são explorados nas aulas de Matemática da escola por motivos diversos. Este contato acontece em eventos realizados nas escolas, onde são apresentadas uma exposição e uma palestra. A ideia norteadora principal do projeto é a de que a aproximação entre os professores de matemática da universidade e de seus alunos de graduação e a comunidade escolar pode favorecer o intercâmbio de problemas e de soluções relacionados ao ensino/aprendizagem e à comunicação de novas e velhas ideias matemáticas e de suas aplicações, além de motivar o interesse do aluno do Ensino Básico pela Matemática.

A metodologia de execução do projeto dá-se em três frentes distintas, que se complementam. A primeira delas, que envolve a coordenação do projeto, busca entrar em contato com as escolas através de visitas presenciais agendadas com a direção, com a finalidade de apresentar o projeto e propor um evento na mesma, constituído de uma exposição, com as atividades lúdicas elaboradas e apresentadas 
pelos alunos de graduação em Matemática, e de uma ou mais palestras, proferidas por convidados, em geral professores da própria UFPR. Além disso, fica a cargo da coordenação juntar os atores fundamentais para o projeto acontecer: os alunos de graduação interessados em participar como bolsistas ou voluntários (aqueles que têm atividades semanais no projeto, da preparação das atividades e materiais concretos, que vão até as escolas para montar e expor as atividades), os alunos colaboradores (que não participam da preparação das atividades, mas que vão até as escolas nos eventos para montar e expor as atividades), os professores orientadores dos alunos bolsistas e voluntários, os palestrantes convidados, que em geral são professores do Departamento de Matemática (DMAT). Outra atuação é conseguir os recursos materiais e logísticos, dentre outras ações de planejamento.

A segunda delas envolve o trabalho de orientação dos alunos bolsistas e voluntários. As professoras orientadoras do projeto se reúnem semanalmente com seu orientandos a fim de sugerir e pesquisar temas interessantes a serem levados nas escolas, materiais adequados para o desenvolvimento dos artefatos concretos, discutir a agenda de visitas, as dificuldades e sucessos encontrados na elaboração e na execução das atividades, elaborar as apresentações obrigatórias e também a escrita de relatórios técnicos e roteiros das atividades desenvolvidas.

Finalmente, a terceira frente diz respeito à atuação do aluno de graduação participante do projeto. Os alunos bolsistas ou voluntários se dedicam entre 6 e 12 horas semanais às atividades do MatematicATIVA. Eles participam de reuniões semanais com suas orientadoras ou com a coordenação do projeto, para tratar do desenvolvimento de suas atribuições, a saber, pesquisar e desenvolver materiais concretos relacionados aos temas escolhidos, bem como se preparar para sua apresentação nas exposições. A preparação das atividades é feita em casa ou na própria universidade, dependendo em geral da escolha do próprio estudante. Quando um evento nas escolas é agendado, mobilizam-se outros atores para atuar na exposição, os alunos colaboradores, que, através de uma espécie de uma oficina, são instruídos pelos alunos bolsistas ou voluntários ou orientadoras ou coordenadoras, a manipular os objetos concretos desenvolvidos e a expô-los como atividade para os alunos do Ensino Básico.

Denominamos de exposição uma apresentação de artefatos concretos relacionados a vários temas matemáticos. Tais artefatos são levados para as escolas ou eventos para serem expostos e manipulados pelo público. Eles são estudados e desenvolvidos pelos alunos de graduação envolvidos no projeto. Em sua maioria, são elaborados 
com materiais de baixo custo como E.V.A. ${ }^{1}$, papel, cordões, latas, e pensados para uso em atividades que façam o público interagir com eles, seja cortando, pintando, ou montando um quebra-cabeça.

As exposições ocorrem, em geral, em espaços amplos sugeridos pela escola, tais como pátios cobertos, auditório, ou mesmo uma sala de aula ampla, onde mesas grandes, ou mesas pequenas reunidas, funcionam como ilhas, em torno da qual os alunos se reúnem em pequenos grupos, sentados ou em pé, dependendo da atividade, e onde um ou mais estudantes de graduação (bolsistas, voluntários ou colaboradores) falam sobre o tema, sobre o artefato e propõem algum desafio a ser resolvido pelos alunos. Tais desafios demandam, dentre outros, percepção geométrica, criatividade e concentração, contudo num clima descontraído e informal.

Ao longo dos 3 anos do projeto foram realizadas várias palestras nos eventos nas escolas. Todas elas foram proferidas por professores do DMAT/UFPR, que após um convite feito à todos os professores do departamento pela coordenação do MatematicATIVA, se disponibilizaram a preparar um conteúdo acessível e interessante para os alunos do Ensino Básico. Um dos desafios enfrentados pela coordenação do projeto foi sincronizar a agenda dos palestrantes com a das escolas. Os títulos abordados nas palestras foram: A traição das imagens e o pensamento visível; Secções de poliedros; A Matemática nas obras de M. C. Escher; Netflix e Sistemas de Equações Lineares; Distâncias: como medí-las?; Fractais; Matemágicas: uma nova forma de multiplicar; Superfícies e nós; e Chips, sistema binário e como contar com os dedos; Uma Introdução à Pesquisa Operacional; e Sistema Terra Lua.

De 2017 ao início de 2020 (antes da pandemia do COVID-19), os locais de execução do projeto MatematicATIVA variaram entre colégios de Ensino Básico da rede pública e eventos de extensão em locais variados cujo público pudesse interagir com os participantes do projeto. Listamos na Tabela 1, por ano, os locais onde o projeto atuou.

Observamos na Tabela 1, que o projeto MatematicATIVA procurou ao longo dos anos, além de atuar nos colégios de Ensino Básico, a atuar em parceria com outras ações de extensão. A sua primeira colaboração, foi com um projeto da UFPR para a Semana Nacional de Ciência e Tecnologia, em que foram levadas várias atividades lúdicas para um público amplo, de alunos de Ensino Básico ao Superior. Esta participação permitiu ao projeto adquirir materiais diversos, que foram empregados para execução das atividades posteriores.

Além disso, o MatematicATIVA levou suas atividades expositivas em eventos

\footnotetext{
${ }^{1}$ Espuma Vinílica Acetinada
} 
Tabela 1: Locais de execução do projeto MatematicATIVA no período de 2017 a 2020

\begin{tabular}{c|c}
\hline Local & Ano \\
\hline Colégio Estadual Professor Júlio Mesquita, Curitiba, PR & 2017 \\
\hline Colégio Estadual Hildebrando de Araújo, Curitiba, PR & 2017 \\
\hline Semana Nacional de Ciência e Tecnologia (UFPR), Curitiba, PR & 2017 \\
\hline Cerimônia de premiação da OPRM, Curitiba, PR & 2017 \\
\hline Colégio Estadual Professor Júlio Mesquita, Curitiba, PR & 2018 \\
\hline Encontro de Extensão e Cultura da UFPR (ENEC), Curitiba, PR & 2018 \\
\hline Semana Nacional de Ciência e Tecnologia, São José dos Pinhais, PR & 2018 \\
\hline Colégio Estadual Professora Maria Balbina, Curitiba, PR & 2018 \\
\hline Cerimônia de premiação da OPRM, Curitiba, PR & 2018 \\
\hline Recepção aos alunos do PSE da 2019 da Matemática (UFPR), Curitiba, PR & 2019 \\
\hline Evento de Extensão "Um dia na Matemática"(UFPR), Curitiba, PR & 2019 \\
\hline Colégio Estadual Polivalente de Curitiba, Curitiba, PR & 2019 \\
\hline Colégio Estadual CQQS, Bocaiúva do Sul, PR & 2019 \\
\hline Colégio Estadual Hildebrando de Araújo, Curitiba, PR & 2019 \\
\hline Colégio Estadual Professora Maria Aguiar Teixeira, Curitiba, PR & 2019 \\
\hline Colégio Estadual Professor Júlio Mesquita, Curitiba, PR & 2019 \\
\hline Setor de Educação Profissional e Tecnológica - SEPT UFPR, Curitiba, PR & 2019 \\
\hline Colégio Estadual Professora Maria Balbina Costa Dias, Curitiba, PR & 2019 \\
\hline Encontro de Extensão e Cultura da UFPR (ENEC), Curitiba, PR & 2019 \\
\hline \hline Meninas nas Exatas: Por Elas para Todos (UFPR), Curitiba, PR & 2020 \\
\hline Signas OPRM - Olina
\end{tabular}

Siglas: OPRM - Olimpíada Paranaense de Matemática; PSE - Processo Seletivo Estendido (terceira fase do vestibular da Matemática/UFPR); CQQS - Conselheiro Quielse Crisóstomo da Silva

Fonte: Autoral.

como cerimônias de premiação de olimpíadas de Matemática, em uma feira expositiva da da cidade de São José dos Pinhais, PR, durante outra Semana Nacional da Ciência e Tecnologia, participou expondo suas atividades e dando oficinas em dois encontros de cultura e extensão da UFPR, e colaborou com o mesmo tipo de atividade expositiva em outros dois eventos de extensão da UFPR. Estas participações, não idealizadas inicialmente no projeto original, ajudaram a divulgar o projeto para a comunidade acadêmica e fora dela, proporcionando inclusive o aumento do interesse dos estudantes de graduação em fazer parte do MatematicATIVA.

Podemos notar também na Tabela 1, que no ano de 2019 houve um aumento significativo no número de colégios contemplados pela visita do MatematicATIVA. Este fato é atribuído à parceria estabelecida com outro projeto de extensão, o "Meninas na Matemática: Procuram-se Arletes", também desenvolvido no DMAT/UFPR. 
Através deste projeto, obtivemos contato com três professoras e um professor de Matemática do Ensino Básico, participantes do mesmo, que colaboraram com o MatematicATIVA no sentido de apresentar a nossa proposta à direção dos seus colégios, agendar as melhores datas para as nossas visitas e também de preparar o local nas suas escolas para as nossas exposições e palestras. Cabe ressaltar, que a participação ativa do professor e das professoras de matemática das escolas trouxe eficiência e agilidade ao projeto, o que permitiu que a coordenação pudesse se dedicar a outros aspectos da execução do mesmo, tais como a logística de reunir, preparar e levar um número significativo de alunos da graduação para a realização das atividades nas escolas.

\subsection{Breve Descrição das Atividades das Exposições}

Nos três primeiros anos do projeto, os temas escolhidos para as exposições foram: Fita de Möbius, Tangrans, Polígonos Replicantes, Simetrias com Livros Espelhos, Mágicas com Cordas (Nós), Pintando Mapas com 4 Cores, Cruz Grega, Cilindro de Sugihara, Torre de Hanói, Cifras de César e Espartana, Estatística com Peixes e Xadrez Africano. Tais temas foram foram escolhidos, pois tinham uma interface bem definida entre o concreto e o abstrato, que poderíamos explorar em termos matemáticos. Buscamos tais temas na literatura sobre Matemática recreativa ou passa-tempos matemáticos [1], [5], [7], [8]. Os alunos bolsistas ou voluntários, se preparavam em termos de investigar a matemática relacionada com cada tema, como ela poderia ser aplicada na vida real, qual a melhor forma de construir os artefatos matemáticos para serem manipulados nas exposições, e escrever roteiros para apresentação das atividades nas exposições.

Para exemplificar, descreveremos uma das atividades, os polígonos replicantes, que são figuras no plano que podem ser dissecadas em diversas cópias idênticas a ela, todas com a mesma forma, só que menores. As figuras podem ter fronteira comum, mas não devem se sobrepor [7, 8]. No MatematicATIVA, esses polígonos foram apresentados nas exposições como quebra- cabeças de quatro peças (as peças dissecadas) e o desafio era montar a mesma forma ampliada, isto é, mantendo-se as proporções entre os lados. As peças foram construídas em E.V.A. com as formas apresentadas nas Figuras 1 e 2.

Geralmente, quebra-cabeças planos com 4 peças costumam ser de rápida resolução. O polígono replicante da esquerda, na Figura 1, é um exemplo e ele é o primeiro a ser entregue ao nosso público. Contudo, o polígono replicante da direita, na Figura 1, não é de solução trivial. Pudemos observar que os alunos tentam re- 

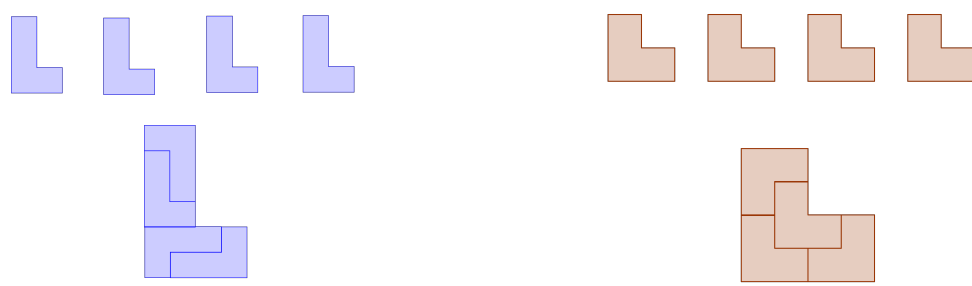

Figura 1: Dois quebra-cabeças de polígonos replicantes com 4 peças. Na parte superior estão as peças. Na parte inferior estão as soluções. Fonte: dos autores.
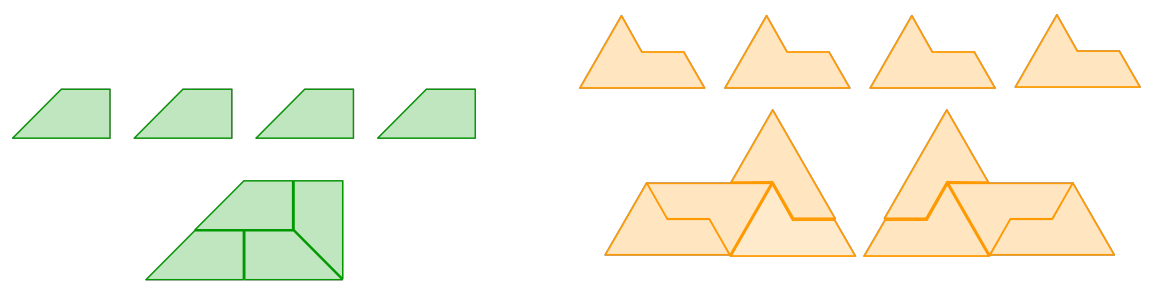

Figura 2: Dois quebra-cabeças de polígonos replicantes com 4 peças. Na parte superior estão as peças. Na parte inferior estão as soluções. Fonte: dos autores.

solvê-lo com a mesma estratégia aplicada ao da esquerda, por terem forma parecida. É nesse ponto que surge a questão de manter a proporcionalidade entre os lados. Muitos identificam prontamente a ausência dela e passam a buscar outra estratégia de resolução, outros acham, erroneamente, que resolveram e é necessário explicar esse conceito e, só a partir de então, passam a buscar uma nova estratégia. Na nova tentativa, o público deve ser criativo e buscar arranjos diferentes para as peças. Eles se debruçam sobre o problema e comemoram quando conseguem. Esse tipo de quebra-cabeça pode ser considerado um problema de insight, "deixam a pessoa que tenta resolver o problema agitando-se para lá e para cá, fazendo pouquíssimo progresso até o instante em que se dá o estalo e a solução aparece. Esses problemas criam pequenas experiências do pensamento criativo e inovador" [6].

Os polígonos replicantes que aparecem na Figura 2, são sugeridos para serem resolvidos na sequência dos anteriormente apresentados. Em especial, eles têm a característica de que sua solução exige pelo menos uma reflexão em torno de alguma reta, diferentemente dos dois primeiros que exigem apenas a rotação em relação a um ponto no mesmo plano dos polígonos. Essa é mais uma estratégia que eles usam automaticamente, ou questionam se podem usar. O Uso do E.V.A. ou outro material com as duas faces com a mesma cor ajuda nesse momento. A Figura 3 mostra um grupo de alunos do Ensino Médio resolvendo os quebra-cabeças dos polígonos replicantes em uma das exposições em 2019. 


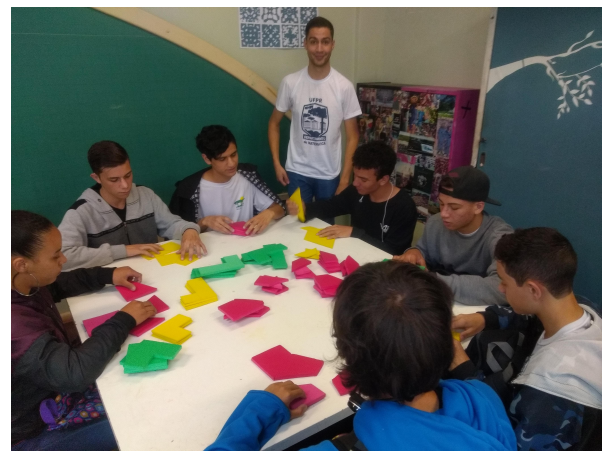

Figura 3: Foto de uma das exposições, com um grupo de alunos sentados em torno de uma mesa, acompanhados por um aluno de gradução, resolvendo os polígonos replicantes. Fonte: dos autores.

\section{Avaliações do Projeto}

Nesta seção apresentaremos os resultados das avaliações realizadas nos três primeiros anos do projeto.

\subsection{Avaliação pelos Alunos de Graduação}

O primeiro tipo de avaliação foi realizada pelos estudantes de graduação envolvidos no projeto e foi feita em dois momentos distintos: uma no final de 2018, aos 17 meses de execução do MatematicATIVA e outra no final de 2019, após 29 meses do seu início. Em ambas as avaliações, todos os graduandos que participaram do projeto, sejam como bolsistas ou voluntários ou colaboradores, foram convidados, por e-mail ou via grupo do Whatsapp, a preencher um questionário online (um Formulário Google) com perguntas objetivas ou subjetivas. A intensão destas perguntas era obter um panorama das impressões dos graduandos sobre a importância do projeto para a comunidade escolar e o impacto do mesmo para a sua formação acadêmica. As perguntas objetivas eram, em geral, uma investigação do grau de satisfação do estudante ou relevância do projeto em relação a um certo assunto, numa escala de zero (insatisfeito ou irrelevante) a cinco (extremamente satisfeito ou relevante), com um pedido de justificativa na sequência, ou eram do tipo sim ou não, seguida de um porquê. Ao final do questionário, pedimos sugestões para o aprimoramento do projeto.

No final de 2018, tivemos doze respostas ao questionário, de um universo de vinte e oito esperadas, ou seja um retorno de 42,8 \% dos estudantes de graduação. Os primeiros questionamentos foram sobre quais exposições o graduando participou, sobre qual material que ele ficou encarregado de apresentar, em qual condição o 
aluno participou do projeto (bolsista, voluntário ou colaborador) e se gostaria de participar novamente do projeto. Para o último questionamento, como uma questão de múltipla escolha, $75 \%$ dos alunos manifestaram seu desejo de participar novamente do projeto. Além disso, tentamos medir o grau de satisfação com o projeto, dividindo esse grau em uma escala de 0 (insatisfeito) a 5 (extremamente satisfeito). A maioria dos alunos ficou bastante satisfeita com o projeto.

Nos outros questionamentos, o objetivo foi obter uma avaliação sobre os assuntos e materiais levados para as exposições. Foi interessante observar que mais de $80 \%$ dos alunos de graduação nunca tinham visto ou manuseado algum dos materiais expostos antes de participar do projeto MatematicATIVA. Isso mostra, e até mesmo explica, a empolgação dos alunos para fazer parte do projeto, mesmo como voluntários ou colaboradores. Os graduandos, em sua maioria, afirmaram que as atividades propostas auxiliam na disciplina de Matemática, e como futuros professores as levariam para a sala de aula, como uma forma de iniciar uma problematização, aguçando o raciocínio lógico, partindo da Matemática concreta para o abstrato, motivando o oposto do que caracteriza uma aula padrão da matéria.

Dentre outros questionamentos, avaliamos o grau de relevância do projeto a partir do ponto de vista do aluno para sua própria formação. A porcentagem dos alunos que avaliaram como extremamente relevante foi $75 \%$. As justificativas para tal se referiram a preparação do aluno para enfrentar a realidade escolar, a questão da prática da comunicação de uma ideia ou resultado matemático; e, também, da necessidade de colocar em prática o que se aprende na Universidade. Do ponto de vista dos estudantes de graduação, o projeto também é extremamente relevante para a comunidade atendida. Muitas sugestões foram dadas para o aperfeiçoamento do projeto e foram incorporadas na Edição 2019 do mesmo.

Já em 2019 o número de respostas ao questionário aumentou. Tivemos 18 respostas de um universo de 27 participantes dentre discentes bolsistas, voluntários e colaboradores. Ou seja, um retorno de $66 \%$ e 94,5\% deles classificaram sua comunicação com o público nas exposições entre 4 e 5, onde 5 representa extremamente satisfatória. Todos afirmaram que o tipo de interação com o público, proporcionada pelas exposições do projeto, é necessária para os estudantes de licenciatura em sua formação. Dentre as diversas justificativas destacam-se:

Levando em consideração toda carga teórica que temos no curso sobre jogos, investigação e também resolução de problemas, o MatematicATIVA permite que essas teorias sejam vistas na prática. Além disso, permite que tenhamos contato com alunos de várias classes sociais, várias realidades, como também a um material de qualidade que dificilmente teríamos 
se o projeto não existisse.

Sim, a interação de alunos com materiais lúdicos é de extrema importância. Capacitando outras áreas do cérebro e desenvolvendo sua criatividade, por mais que sejam simples, as atividades utilizam um raciocínio profundo, as atividades fogem da monotonia das aulas expositivas, o que agrega em mais estímulos para a participação dos envolvidos.

Com relação ao grau de satisfação com o projeto, o percentual de $94,4 \%$ dos alunos classificou como 4 ou 5 , sendo que a grande maioria $(72,2 \%)$ declarou-se como extremamente satisfeita (5). Somente $11 \%$ declarou que não participaria novamente do projeto. Novamente, 94,4\% acreditam que os materiais apresentados nas exposições contribuem para a disciplina de Matemática. Um dos que não acredita justificou da seguinte maneira: "Acho os jogos divertidos, mas não acho que eles tenham um contato com a matemática que fique claro para os alunos.". Em contrapartida, um dos que diz acreditar afirmou que "Todos os materiais e brincadeiras apresentados estimulam o raciocínio lógico, fundamental para a compreensão de qualquer conteúdo da disciplina de Matemática.". O percentual de 100\% dos alunos disse que levaria algum dos materiais para a sua sala de aula e é interessante notar novamente que $77,8 \%$ destes alunos nunca tinham manuseado algum material da exposição e 94,4\% dos alunos acharam as explicações dadas de fácil compreensão.

Quanto às opiniões sobre o grau de relevância do projeto para a comunidade, $100 \%$ deles deram classificação 4 ou 5, onde 5 é extremamente relevante. Podemos destacar as seguintes justificativas dadas para isso:

O projeto é importantíssimo, pois aproxima a graduação de Matemática das escolas, entrega atividades matemáticas de um jeito mais diferente e participativo do que o habitual e ainda permite que os alunos tirem suas dúvidas sobre a graduação em Matemática. Várias vezes fui questionado se estava gostando do curso, como foi o PSE, como funciona a separação do curso em licenciatura e bacharelado, etc. Essas são dúvidas frequentes que eu também tive antes de entrar na graduação, e fiquei muito satisfeito em poder esclarecer algumas dessas coisas aos futuros matemáticos que encontrei no projeto.

O projeto é de grande relevância pois atrela todos os pilares básicos da universidade, que são ensino, pesquisa e extensão. A extensão, exclusivamente, é necessária para estarmos atuando num ponto deficitário da nossa sociedade, e a matemática com certeza é um ponto assim, o ensino da matéria é muito fechado e centralizado em regras e mais regras, e sabemos que a matemática é muito além disso. 
Quanto ao grau de relevância do projeto para a sua formação acadêmica, $94 \%$ classificou entre 4 e 5 , onde 5 é extremamente relevante. Um dos alunos declarou:

\begin{abstract}
Acho que mesmo quem pretende cursar o bacharelado, como eu, só possui vantagens em participar do projeto, pelo menos como voluntário em algumas visitas, pois além de não tomar muito tempo, é uma experiência muito agradável e funciona como um treinamento de didática ao explicar as coisas para os alunos, onde cada um possui seu nível de entendimento. Entender a dificuldade do aluno e adaptar sua explicação para que ele entenda melhor é algo que todo matemático precisa saber.
\end{abstract}

\title{
3.2 Avaliação pelos alunos do Ensino Básico
}

O segundo tipo de avaliação foi realizada pelos estudantes do Ensino Básico, público do projeto, no ano de 2019. Ao final de cada evento nas escolas, um questionário impresso era entregue aos alunos com perguntas objetivas sobre a opinião deles em relação à exposição e à palestra e à organização do evento de um modo geral. Cabe esclarecer que nos dois primeiros anos do projeto, 2017 e 2018, optamos por aplicar os questionários num dia posterior ao evento, deixando-os nas escolas com um de nossos contatos, para que fossem aplicados aos alunos que participaram do evento. Entretanto, com essa estratégia o número de questionários que retornaram para o projeto foi insignificante.

No questionário feito, a maioria das perguntas eram objetivas e de múltipla escolha, nas quais as escolhas poderiam ser ótimo, bom, regular e ruim. Uma única pergunta, sobre o quanto eles acharam que o evento estimulou o interesse deles pela Matemática, tinha como escolhas possíveis: nenhum pouco, pouco, consideravelmente ou muito. Apresentaremos aqui apenas a análise a essas perguntas.

Para facilitar a apresentação dos dados, denominaremos de Colégio A o Colégio Estadual Polivalente de Curitiba, que teve 90 alunos participantes do Fundamental II, Colégio B o Colégio Estadual CQQS, com 90 alunos participantes do Ensino Médio, Colégio C o Colégio Estadual Hildebrando de Araújo, com 202 alunos participantes do Ensino Médio e Técnico Integrado de Administração, sendo 180 do Matutino e 22 do noturno, Colégio D o Colégio Estadual Professora Maria Aguiar Teixeira, com 100 alunos participantes do Ensino Médio, Colégio E o Colégio Estadual Professor Júlio Mesquita, com 200 alunos participantes do Ensino Fundamental II, Colégio F o Setor de Educação Profissional e Tecnológica - SEPT UFPR, com 23 alunos participantes do Ensino Médio e Técnico e Colégio G o Colégio Estadual Professora Maria Balbina Costa Dias, com 45 alunos participantes do EJA Fase II (Ensino Fundamental II) e Ensino Médio. Para o Colégio C, dividiremos as res- 
postas entre Colégio CM, que se refere ao turno matutino, em que o número de participantes foi significativamente maior, e CN, que se refere ao turno noturno. As respostas de cada colégio para cada pergunta, são apresentadas nas Tabelas 2-5. Na Tabela 5, as últimas duas colunas aparecem em branco para o Colégio A, pois houve um erro na formulação pergunta entregue para ser respondida nesse colégio.

Tabela 2: Percentual das respostas dos alunos do EB às perguntas: (1) Qual á sua avaliação sobre a iniciativa em realizar este evento? (2) Como você avalia a organização do evento (atendimento, local, horário e material didático)?

\begin{tabular}{c||c|c||c|c}
\hline Local & $\begin{array}{c}\text { Pergunta 1 } \\
\text { Boa ou ótima }\end{array}$ & $\begin{array}{c}\text { Pergunta 1 } \\
\text { Ótima }\end{array}$ & $\begin{array}{c}\text { Pergunta 2 } \\
\text { Boa ou ótima }\end{array}$ & $\begin{array}{c}\text { Pergunta 2 } \\
\text { Ótima }\end{array}$ \\
\hline \hline Colégio A & $80,4 \%$ & $50 \%$ & $77,2 \%$ & $40,2 \%$ \\
\hline Colégio B & $97,3 \%$ & $83,6 \%$ & $100 \%$ & $76,7 \%$ \\
\hline Colégio CM & $85,4 \%$ & $40,6 \%$ & $81,2 \%$ & $30,2 \%$ \\
\hline Colégio CN & $100 \%$ & $61,5 \%$ & $100 \%$ & $61,5 \%$ \\
\hline Colégio D & $100 \%$ & $68,8 \%$ & $97,15 \%$ & $54,3 \%$ \\
\hline Colégio E & $100 \%$ & $100 \%$ & $100 \%$ & $66,7 \%$ \\
\hline Colégio F & $100 \%$ & $86,4 \%$ & $100 \%$ & $63,9 \%$ \\
\hline Colégio G & $100 \%$ & $72 \%$ & $100 \%$ & $88 \%$ \\
\hline
\end{tabular}

Tabela 3: Percentual das respostas dos alunos do EB às perguntas: (3) Qual a sua avaliação sobre o conteúdo apresentado na palestra (caso você tenha assistido)? (4) Como você avalia o desempenho didático do(a) palestrante (caso você tenha assistido)?

\begin{tabular}{c||c|c||c|c}
\hline Local & $\begin{array}{c}\text { Pergunta 3 } \\
\text { Bom ou ótimo }\end{array}$ & $\begin{array}{c}\text { Pergunta 3 } \\
\text { Ótimo }\end{array}$ & $\begin{array}{c}\text { Pergunta 4 } \\
\text { Bom ou ótimo }\end{array}$ & $\begin{array}{c}\text { Pergunta 4 } \\
\text { Ótimo }\end{array}$ \\
\hline \hline Colégio A & $78,3 \%$ & $43 \%$ & $84,7 \%$ & $55,4 \%$ \\
\hline Colégio B & $94,5 \%$ & $67,1 \%$ & $98,7 \%$ & $83,6 \%$ \\
\hline Colégio CM & $65,6 \%$ & $19,8 \%$ & $68,8 \%$ & $32,3 \%$ \\
\hline Colégio CN & $100 \%$ & $61,5 \%$ & $100 \%$ & $84,6 \%$ \\
\hline Colégio D & $92,3 \%$ & $46,35 \%$ & $89,65 \%$ & $57,9 \%$ \\
\hline Colégio E & $100 \%$ & $91,7 \%$ & $91,6 \%$ & $83,3 \%$ \\
\hline Colégio F & $81,8 \%$ & $31,8 \%$ & $54,5 \%$ & $31,8 \%$ \\
\hline Colégio G & $95,5 \%$ & $87,5 \%$ & $95,5 \%$ & $92 \%$ \\
\hline
\end{tabular}

Apesar da diversidade do público, incluindo alunos do Fundamental II, da Educação de Jovens e Adultos, do Ensino Médio e do Técnico, e também da diversidade associada ao turno escolar (matutino, vespertino e noturno), observando as Tabelas 2 - 
Tabela 4: Percentual das respostas dos alunos do EB às perguntas: (5) Qual é sua avaliação sobre o conteúdo apresentado na exposição? (6) Como você avalia o desempenho didático dos expositores?

\begin{tabular}{c||c|c||c|c}
\hline Local & $\begin{array}{c}\text { Pergunta 5 } \\
\text { Bom ou ótimo }\end{array}$ & $\begin{array}{c}\text { Pergunta 5 } \\
\text { Ótimo }\end{array}$ & $\begin{array}{c}\text { Pergunta 6 } \\
\text { Bom ou ótimo }\end{array}$ & $\begin{array}{c}\text { Pergunta 6 } \\
\text { Ótimo }\end{array}$ \\
\hline \hline Colégio A & $72,8 \%$ & $42,2 \%$ & $84,5 \%$ & $55,6 \%$ \\
\hline Colégio B & $97,3 \%$ & $64,4 \%$ & $100 \%$ & $67,1 \%$ \\
\hline Colégio CM & $83,4 \%$ & $43,8 \%$ & $83,3 \%$ & $44,8 \%$ \\
\hline Colégio CN & $92,4 \%$ & $46,2 \%$ & $92,3 \%$ & $61,5 \%$ \\
\hline Colégio D & $100 \%$ & $64,25 \%$ & $100 \%$ & $64,95 \%$ \\
\hline Colégio E & $100 \%$ & $90,9 \%$ & $91,7 \%$ & $75 \%$ \\
\hline Colégio F & $100 \%$ & $90,5 \%$ & $100 \%$ & $76,2 \%$ \\
\hline Colégio G & $92 \%$ & $68 \%$ & $100 \%$ & $24 \%$ \\
\hline
\end{tabular}

Tabela 5: Percentual das respostas dos alunos do EB às perguntas: (7) Como você avalia a forma de apresentação dos temas desenvolvidos na exposição? (8) Quanto você acha que este evento estimulou seu interesse pela Matemática?

\begin{tabular}{c||c|c||c|c}
\hline Local & $\begin{array}{c}\text { Pergunta 7 } \\
\text { Boa ou ótima }\end{array}$ & $\begin{array}{c}\text { Pergunta 7 } \\
\text { Ótima }\end{array}$ & $\begin{array}{c}\text { Pergunta 8 } \\
\text { Consideravelmente ou muito }\end{array}$ & $\begin{array}{c}\text { Pergunta 8 } \\
\text { Muito }\end{array}$ \\
\hline \hline Colégio A & $73 \%$ & $44,9 \%$ & & \\
\hline Colégio B & $98,6 \%$ & $66,7 \%$ & $58,9 \%$ & $12,3 \%$ \\
\hline Colégio CM & $81,3 \%$ & $34,4 \%$ & $35,5 \%$ & $3,2 \%$ \\
\hline Colégio CN & $100 \%$ & $69,2 \%$ & $62,6 \%$ & $23,1 \%$ \\
\hline Colégio D & $98,8 \%$ & $64,05 \%$ & $77,4 \%$ & $38,7 \%$ \\
\hline Colégio E & $100 \%$ & $83,3 \%$ & $91,6 \%$ & $83,3 \%$ \\
\hline Colégio F & $100 \%$ & $66,7 \%$ & $80 \%$ & $40 \%$ \\
\hline Colégio G & $100 \%$ & $80 \%$ & $78,3 \%$ & $43,5 \%$ \\
\hline
\end{tabular}

5, podemos perceber que a avaliação do projeto feita pelos alunos do Ensino Básico é muito positiva.

A Tabela 2 mostra que os alunos gostaram da ideia do evento e da maneira como ele foi organizado nas escolas, sendo que $80,4 \%$ ou mais de respostas "boa ou ótima" foram dadas para a iniciativa de realizar o evento e $77,2 \%$ ou mais de respostas "boa ou ótima" foram dadas para a organização.

No que se refere às perguntas sobre as palestras (Tabela 3), as porcentagens de respostas "bom ou ótimo" foram também bastante altas. Quanto às exposições, a aprovação também foi altíssima na maioria dos colégios, com porcentagens de "bom 
ou ótimo"igual ou acima de $72 \%$ (Tabelas 4 e 5).

$\mathrm{Na}$ Tabela 5, em suas duas últimas colunas, aparecem as porcentagens de respostas à pergunta "Quanto que você acha que este evento estimulou seu interesse pela matemática?". Podemos observar que, em 5 eventos, a porcentagem de respostas "consideravelmente ou muito" ficou maior ou igual a $62 \%$. Esses valores são bons, mas gostaríamos de ter valores mais altos ainda. Esta avaliação nos aponta para a necessidade de fazer uma ponte ainda maior entre o lúdico que é apresentado nos eventos e a Matemática mais formal apresentada na maioria das salas de aula.

\section{Conclusão}

Tanto das avaliações com os estudantes de graduação quanto das avaliações com os estudantes do Ensino Básico, podemos concluir que a interação mediada pela Matemática e gerada pelo projeto MatematicATIVA teve um impacto bem grande e positivo nos dois grupos. Além de todas as informações obtidas pelas pesquisas relatadas na Seção 3 podemos ainda citar os depoimentos obtidos de conversas informais com os alunos de graduação. Um dos mais marcantes é o de um aluno de início de graduação, indeciso ainda se permanecia no curso ou não, que após ter participado como colaborador em uma das exposições do projeto, disse que aquela participação o fez ter certeza do que ele queria, e o que ele queria era realmente se tornar um professor de Matemática.

Por outro lado, observamos que são necessárias ações de diversas naturezas para estimular o interesse pela Matemática nos estudantes de Ensino Básico. Neste sentido, o projeto MatematicATIVA contribuiu realizando diversos eventos isolados, que tiveram o papel de mostrar que a Matemática pode ser apresentada de maneira lúdica e estimulante. Contudo, percebemos que seria de grande importância, um projeto que estendesse as atividades das exposições para além de um evento isolado. Tais atividades poderiam ainda ser incluídas nas próprias aulas de Matemática.

\section{Agradecimentos}

As autoras deste trabalho agradecem: à professora Heily Wagner, pela sua fundamental participação como coordenadora, no início do MatematicATIVA; à professora Elizabeth Wegner Karas e aos demais participantes do Projeto "Meninas na Matemática: Procuram-se Arletes", pela valiosa colaboração no ano de 2019; à Fundação Araucária e à UFPR, pela bolsa de extensão universitária concedida à 
quarta autora e pelas demais bolsas concedidas aos alunos de graduação participantes do projeto MatematicATIVA; e, finalmente, a todos os participantes do projeto, que foram fundamentais para a realização do mesmo.

\section{Referências}

[1] ADAMS, C. C.; The Knot Book: An Elementary Introduction to the Mathematical Theory of Knots. Providence: American Mathematical Society, 2004.

[2] Biênio da Matemática Brasil, Disponível em: <https://www.bieniodamatematica.org.br> Acesso em: 03 de maio de 2019.

[3] Festival da Matemática 2017, Disponível em: <http://festivaldamatematica.org.br> Acesso em: 03 de maio de 2019.

[4] HOWSON, A., KAHANE, J., POLLAK, H.; ICMI Study n. ${ }^{\text {0 }}$ 4. La popularización de las matemáticas, Pág. 071-078, SUMA, no. 2, 1989.

[5] MALAGUTTI, P. L; SAMPAIO, J. C.; Mágicas, Matemática e outros Mistérios. São Carlos: EdUFSCar, 2008.

[6] PERKINS, D. N.; A banheira de Arquimedes: como os grandes cientistas usaram a criatividade e como você pode desenvolver a sua. Rio de Janeiro: Ediouro, 2001.

[7] STEWART, I; Almanaque das Curiosidades Matemáticas. Rio de Janeiro: Zahar, 2009.

[8] STEWART, I; Incríveis Passatempos Matemáticos. Rio de Janeiro: Zahar, 2010. 